\title{
EVALUATING THE IMPACT OF WORKED EXAMPLE VIDEOS FOR BLENDED LEARNING IN A LARGE-ENROLMENT BUSINESS STATISTICS COURSE
}

\author{
SARAH DART \\ Queensland University of Technology \\ sarah.dart@qut.edu.au
}

\begin{abstract}
Statistics courses are frequently perceived by tertiary students as extremely difficult and anxietyinducing, negatively impacting student outcomes and experiences. To address this, the present study considered worked example videos (where an instructor demonstrates the solution to a problem while narrating the process) as a blended learning approach for enhancing an introductory business statistics course taken by 2265 students over three semesters. Impact was evaluated with video usage, academic performance, and student survey data. Students utilised worked example videos heavily before assessment deadlines, frequently employing active learning strategies during their engagements. Improvements in academic performance and course satisfaction were observed compared to previous cohorts. This demonstrates worked example videos are well-suited to largeenrolment courses due to their highly scalable capacity to deliver timely support for learning, which individuals can tailor to their diverse needs.
\end{abstract}

Keywords: Statistics education research; Educational videos; Problem-solving; Active learning; Academic performance; Course satisfaction

\section{INTRODUCTION}

As we move toward a world in which data are increasingly leveraged as decision-making tools, skills in statistical analysis and interpretation are becoming critically important (Brynjolfsson \& McElheran, 2016). Consequently, there is a growing expectation that university graduates are statistically literate, with further capabilities in applying statistical reasoning and statistical thinking to real-world problems (Lai et al., 2017). In the context of undergraduate business programs, these expectations are reflected in the standards of accrediting bodies such as the Association to Advance Collegiate Schools of Business who require graduates to demonstrate "evidence-based decisionmaking...including the application of statistical tools and techniques" (2018, p. 35). Many undergraduate business programs seek to address this through introductory statistics courses (Songsore $\&$ White, 2018). These courses, however, are frequently perceived by students as extremely difficult and anxiety-inducing, which often translates to high failure rates and poor student satisfaction (Berenson et al., 2015; Lai et al., 2017; Nguyen et al., 2016). Given that students who develop negative perceptions of statistics are less likely to utilise them effectively in their future practice (Schau \& Emmioğlu, 2012; Songsore \& White, 2018), a transformational shift is needed in how statistical learning is facilitated at the undergraduate level.

The provision of video resources can play a major role in enhancing learning in higher education (Lai et al., 2017). This is realised through the accessibility, flexibility, and personal agency videos offer over traditional face-to-face settings, which has in turn enabled the development of innovative learning environments and pedagogical designs (Ma'arop \& Embi, 2016). Rather than only delivering course material fully online, however, the blending of online and face-to-face components has gained significant traction (Ma'arop \& Embi, 2016) as it allows students to capitalise on the convenience of online delivery while preserving the interaction and social learning well-suited to face-to-face environments (Owston et al., 2019).

An approach to blended learning that has emerged in the science, technology, engineering, and mathematics (STEM) disciplines involves using worked example video (WEV) resources, also known as video screencasts. Underpinned by self-regulated learning (Zimmerman, 2002) and multimedia 
learning theories (Mayer, 2008), WEVs show potential for improving learning outcomes and student satisfaction in subject areas with a substantial problem-solving focus (Ahmad et al., 2013; Dart, Pickering, et al., 2020; Martin, 2016). Moreover, the approach offers scalability, which is an important consideration in large-enrolment classes that typically face greater challenges delivering high-quality student experiences (Gannaway et al., 2018; Owston et al., 2019). Taking this background into account, this study aims to evaluate the impact of WEVs as a blended learning approach in a large business statistics course with historically low academic performance outcomes and student satisfaction. Usage of the WEVs (including common learning strategies for engagement) as well as impact on academic performance and course satisfaction are explored.

\section{BACKGROUND}

\subsection{CHALLENGES IN LEARNING AND TEACHING STATISTICS}

There are a range of individual and environmental factors that influence student attitudes and performance in statistics courses. Mathematical skill levels and prior knowledge are one critically important aspect, as students with well-developed learning strategies and prior exposure to statistical concepts are more likely to be academically successful (Ali \& Iqbal, 2012; Intepe \& Sheaman, 2020; Onwuegbuzie \& Wilson, 2003). However, widening participation trends have grown the proportion of students without traditional preparation (such as mature-age learners), meaning there is an increasing cohort who lack a background in statistics (Dart \& Spratt, 2021; Nguyen et al., 2016). Moreover, in Australia where the present study was performed, a steady decline in students choosing to study higherlevel mathematics in high school has occurred over the last decade (Barrington \& Evans, 2016). This combined with Australian universities removing formal prerequisites for admission (Office of the Chief Scientist \& Australian Mathematical Institute, 2020) has meant a lack of mathematics preparation at the undergraduate level even for school-leavers (Intepe \& Sheaman, 2020; King \& Cattlin, 2015). Consequently, there is a growing need to bridge students without an ideal educational background for attempting statistics courses (Dart \& Spratt, 2021). Given the flexibility and personal agency associated with video resources, blended designs, which offer video material as a supplement to existing face-toface teaching, pose an attractive option.

Statistics anxiety, defined as "anxiety which occurs when a student encounters statistics in any form and at any level" (Onwuegbuzie \& Wilson, 2003, p. 196) is a phenomenon widely recognised in the literature. Up to $80 \%$ of students experience statistics anxiety, and this directly inhibits the efficiency of students' memory processes when learning statistical content (Onwuegbuzie \& Wilson, 2003). Unsurprisingly then, statistics anxiety has been shown to correlate with poorer performance in statistics courses (Ali \& Iqbal, 2012; Onwuegbuzie \& Wilson, 2003). Factors that directly contribute to statistics anxiety include time pressure (Kinkead et al., 2016) and fear of asking for help, especially from an instructor (Hamid \& Sulaiman, 2014). Videos have the potential to tackle these challenges given they can serve as a self-help resource that allow students to engage at their own pace. Additionally, it has been shown that students in blended and online learning environments feel less threatened to seek help than those in traditional learning environments (Kitsantas \& Chow, 2007).

\subsection{WORKED EXAMPLES FOR LEARNING}

Worked examples provide an expert's step-by-step solution to a problem that forms an exemplar for students to unpack and emulate (Ayres \& Sweller, 2013). They are an effective tool for developing students' problem-solving skills (e.g., ability to complete a statistical procedure), so are often used in the STEM disciplines which have a strong problem-solving focus (Kant et al., 2017). Worked examples have been shown especially useful for novice learners who lack domain-specific knowledge (Ayres \& Sweller, 2013). This is because the highly structured step-by-step approach imposes a reduced cognitive load, enabling the student to learn the intended problem-solving skills without becoming tied up in peripheral information (Ayres \& Sweller, 2013). Consequently, learning via worked examples has been shown to produce enhanced learning outcomes within shorter timeframes compared to other techniques like discovery learning and straight problem-solving practice (Kant et al., 2017). 
Historically, worked examples have been presented live in face-to-face classes or as written documents to aid self-directed study. WEVs, generated by recording the solution to a problem while narrating the process (Ahmad et al., 2013), however, have become more prevalent as availability of recording devices, editing software, and dissemination platforms has increased (Kay, 2012). WEVs have advantages over live demonstration as the asynchronous delivery allows students to view the material at a time and a place of their choosing, while gaining control over their viewing experience through pausing, replaying and skipping functionality (Kay, 2012). Moreover, the video format improves upon written solution documents through the narration communicating the reasoning behind the problem-solving process. In fact, Belski (2011) showed engineering students who used WEVs achieved higher grades compared to those using equivalent written solutions. Similarly, Mohamad Ali et al. (2011) showed students using narrated screencasts significantly outperformed those who watched screencasts without narration when learning Flash software.

\subsection{THEORETICAL PERSPECTIVES FOR LEARNING WITH WORKED EXAMPLE VIDEOS}

There are two key theories that contribute to explaining the effectiveness of WEVs for learningself-regulated learning theory and the cognitive theory of multimedia learning. Collectively, these theories provide a basis for explaining how active learning (defined by students engaging in "handson" activities as opposed to participating passively in lectures) occurs in the learning environment afforded by WEVs (Mayer \& Moreno, 2003; Moos \& Bonde, 2016).

First, self-regulated learning can be defined as "learning that involves the regulation and monitoring of cognition, behaviour, and motivation, and the active construction of knowledge by using strategies and goals" (Moos \& Bonde, 2016, p. 237). Here learning is conceptualised as an activity students engage in proactively, rather than an event that happens to them as a result of teaching (Zimmerman, 2002). According to self-regulated learning theory, students progress cyclically through three phases: forethought, performance, and self-reflection (Zimmerman, 2002). The forethought phase involves establishing learning goals, which are influenced by students' motivation orientations (Moos \& Bonde, 2016). Students then employ strategies to pursue these goals during the performance phase (Hattie \& Donoghue, 2016; Zimmerman, 2002). Critically, students continuously monitor their progress, and adapt their cognition, behaviours, and motivations in response to self-identified gaps between their current and desired states of achievement (Moos \& Bonde, 2016). WEVs can play a significant role in supporting meta-cognitive monitoring through enhancing the accuracy of students' self-assessments. This is achieved through the implicit feedback students receive through WEVs (Nicol \& MacfarlaneDick, 2006). This feedback is also enriched through the narration that rationalises the reasoning behind solution processes and tackles misconceptions explicitly. The final self-reflection phase of selfregulated learning occurs when students assess and evaluate reasons for their performance, which in turn influences motivation orientations (Moos \& Bonde, 2016).

The second theory, the cognitive theory of multimedia learning, is based on assumptions that humans process visual and verbal information through separate channels that each have limited capacity (Mayer, 2008; Sweller et al., 2019). For deep learning to occur, students must process the information streams actively by selecting, organising, and then integrating the information with prior knowledge (Mayer, 2008). Consequently, learning via multimedia is enhanced when delivery is split effectively between the visual and verbal channels, and when students are supported to select, organise, and position critical information in their working memory (Mayer, 2008). WEVs are able to take advantage of these factors by employing complementary visual and audio components, presenting explanations as narration rather than printed text, clearly signposting vital information (while minimising the superfluous), and developing videos in learner-paced segments (Mayer \& Moreno, 2003). Additionally, using a conversational (rather than formal) delivery style supports cognitive processing through creating a social partnership that encourages the learner to try harder in understanding the instructor (Mayer, 2008). 


\subsection{BLENDED LEARNING DESIGNS}

Blended learning has emerged as a major global trend in higher education (Dziuban et al., 2018; Ma'arop \& Embi, 2016) as it brings together the best of what online and face-to-face environments have to offer, while minimising their respective shortcomings (Owston et al., 2019). Utilising a multi-modal approach also promotes learning as a continuous process that can take many forms, in turn fostering learning independence and self-direction (Ma'arop \& Embi, 2016). It has been shown that students prefer blended learning designs (Owston et al., 2019), and courses designed around blended learning typically produce superior progression and retention rates compared to those delivered purely face-toface or online (Dziuban et al., 2018; Moskal et al., 2013). This improved performance is largely attributed to the inclusion of active learning pedagogy (Deslauriers et al., 2019; Freeman et al., 2014; Vaughan, 2007).

Despite the benefits associated with blended learning, instructors can be reluctant to incorporate it due to the time commitment required to redevelop learning materials, pedagogical and technological skill gaps, and fear of student resistance that would risk lowering student evaluation of teaching scores (Ma'arop \& Embi, 2016; Vaughan, 2007). These issues are highly prevalent in models like the "flipped classroom", in which students watch videos prior to attending face-to-face classes designed around active learning (Karabulut-Ilgu et al., 2018). Significant redevelopment and upskilling are associated with the transition to this model, while student resistance can be a major issue as learners are required to adjust to taking greater responsibility for their learning (Deslauriers et al., 2019; Karabulut-Ilgu et al., 2018; Vaughan, 2007). Students can also choose not to engage with online materials due to disinterest, lack of time management, or technical difficulties, which negatively impacts effectiveness of the face-to-face activities (Karabulut-Ilgu et al., 2018). These challenges are further amplified in large-enrolment courses that encounter greater logistical challenges, heightened cohort diversity, and where the quantity and quality of interactions among students and instructors is reduced (Owston et al., 2019).

An approach that shows promise for addressing the abovementioned challenges of the flipped classroom model while still incorporating active learning opportunities is using WEVs to supplement face-to-face experiences (Lai et al., 2017). Here WEVs are provided as an optional follow-up activity designed to accommodate students with different needs (such as limited prerequisite knowledge or extension; Ahmad et al., 2013). Although developing WEVs requires technical skills, studies have shown that low production quality WEVs using an informal tone are actually more effective than professionally produced recordings (Guo et al., 2014). Moreover, WEVs can be reused from one teaching period to the next offering significant scalability. Furthermore, providing WEVs as a supplement means instructors are not required to redevelop existing classroom materials or upskill in new classroom facilitation techniques. There is evidence WEVs facilitate active learning directly through students solving problems alongside the videos (Dart, Pickering, et al., 2020; Martin, 2016). This personal agency and voluntary nature of the interactions can mitigate against student resistance, addressing a further barrier to implementation for instructors.

\subsection{PREVIOUS STUDIES OF WEVS IN HIGHER EDUCATION}

A key area of interest in previous WEV studies has been the relationship between video usage and students' academic performance. Several studies have shown WEVs improve performance; for example, Belski (2011) and Martin (2016) in engineering, He et al. (2012) and Key and Paskevicius (2015) in chemistry, and Loch et al. (2014) in mathematics. Very few studies, however, have investigated this for statistics courses taken by students in non-STEM majors. DeVaney (2009) implemented WEVs in an online statistics course taken by 78 education students. Positive student attitudes toward the videos were recorded, but no difference in academic performance was observed. Lloyd and Robertson (2011) produced a 12-minute video to examine the difference between text-based and video-based tutorials on a cohort of 53 psychology students studying statistics. Those utilising the video demonstrated enhanced learning outcomes, especially for higher-order conceptual statistics knowledge. More recently, Lai et al. (2017) introduced $40 \mathrm{WEVs}$ into an introductory business statistics class taken by 73 students, concluding that students performing around the $\mathrm{B}$ and $\mathrm{C}$ level benefitted most from the intervention. 
Other aspects of WEVs that have been investigated include student approaches to and motivations for engagement. Both Dart, Pickering et al. (2020) and Martin (2016) showed that engineering students frequently solved problems presented in WEVs, with students often pausing to work ahead, and then restarting the videos to get hints when stuck or to verify solutions. Students also described replaying sections of WEVs to fully comprehend the reasoning behind the problem-solving process. Although students report using WEVs throughout the semester to clarify understanding and catch-up following missed classes (Ahmad et al., 2013; Dart, Pickering, et al., 2020; Martin, 2016), assessment has been consistently demonstrated as the most significant usage motivator (Ahmad et al., 2013; Belski, 2011; Dart, Pickering, et al., 2020; Key \& Paskevicius, 2015). This has translated to major usage peaks in the lead-up to assessment deadlines, particularly exams (Belski, 2011; Dart, Pickering, et al., 2020; Key \& Paskevicius, 2015).

There is significant variation in the contexts previous WEV studies have been conducted in. For example, WEVs have been developed as a one-off resource (Lloyd \& Robertson, 2011), as a mechanism for supporting students studying fully online (DeVaney, 2009), to aid students preparing for specific assessment (Key \& Paskevicius, 2015), and to increase accessibility of solutions demonstrated in faceto-face classes (Martin, 2016). The vast majority of WEV studies have also used sample sizes of less than 100 students (Belski, 2011; DeVaney, 2009; He et al., 2012; Lai et al., 2017; Lloyd \& Robertson, 2011; Loch et al., 2014; Martin, 2016). Consequently, the impact of WEVs as a blended learning approach in large-enrolment courses remains a significant gap in the literature. This is especially the case for introductory statistics courses, which are known to face additional challenges around student outcomes and experiences (Berenson et al., 2015; Nguyen et al., 2016). The present study aims to address this by implementing WEVs as a blended learning approach in a large-enrolment business statistics course for the purpose of improving academic performance and student satisfaction. Usage of the WEVs and the resulting impact on academic performance and course satisfaction are examined.

\section{RESEARCH DESIGN}

\subsection{PARTICIPANTS AND SETTING}

The present study forms part of a larger project conducted at the Queensland University of Technology; a large Australian university situated in metropolitan Brisbane. While previous work has examined WEVs in engineering courses (Dart, Cunningham-Nelson, et al., 2020; Dart, Pickering et al., 2020), considered here is the introductory statistics course entitled "Data Analysis", which was mandatory for students in the Bachelor of Business. Course topics included presenting data, probability, normal distributions, hypothesis testing, linear regression, time series, and forecasting. In addition to developing conceptual understanding, students were expected to perform simple manual calculations as well as apply concepts to larger datasets using Microsoft Excel (similar to what was demonstrated in WEVs). The course had no prerequisites and students were only assumed to have passed lower-level senior high school mathematics (known as Maths A) to enter the program. This meant a significant cohort had no prior exposure to higher-level concepts such as hypothesis testing and regression.

The course was taught on-campus over thirteen teaching weeks during Semesters 1 and 2, and eleven teaching weeks for the Summer Semester. Teaching periods also included a mid-semester break and final exam block. Delivery was through weekly two-hour lectures and 1.5-hour tutorials. Assessment comprised six progressive homework assignments (weighted at 20\%), followed by a larger research report (weighted at 30\%), and a final exam (weighted at 50\%). Course coordination varied between two academics - one primarily led the course during Semesters 1 and 2, while the other led Summer Semesters (but ran repeat lectures and tutorials in other teaching periods). Up to 12 tutors were employed for Semesters 1 and 2, but the course coordinator facilitated all activities in the Summer Semester. The instructor who produced WEVs was only engaged in this capacity.

The cohorts enrolled during 2018, encompassing 2265 students in total, were exposed to the WEVs. Cohorts who took the course in the two years prior (when WEVs were not available) were considered controls for comparison. Demographic characteristics are shown in Table 1 where it can be seen there were significant differences in cohort size and background characteristics across the teaching periods. For example, Summer Semesters were much smaller, and attracted fewer domestic and school-leaver 
pathway students. These differences in underlying cohort characteristics need to be considered when evaluating the impact WEVs had, discussed in the data analysis section below.

Table 1. Characteristics of student cohorts and satisfaction survey response rates.

\begin{tabular}{lccccccccc}
\hline $\begin{array}{l}\text { Cohort Year and } \\
\text { Teaching Period }\end{array}$ & 2016 & 2016 & 2016 & 2017 & 2017 & 2017 & 2018 & 2018 & 2018 \\
\hline SEM Availability & No & No & No & No & No & No & Yes & Yes & Yes \\
Student Enrolments & 1169 & 757 & 163 & 1254 & 843 & 171 & 1263 & 875 & 127 \\
\hline Cohort Characteristics (\%) & & & & & & & & & \\
\hline Female & 52 & 48 & 55 & 51 & 52 & 55 & 51 & 52 & 51 \\
Domestic & 88 & 84 & 63 & 84 & 84 & 54 & 87 & 85 & 58 \\
School-Leaver & 44 & 38 & 15 & 41 & 41 & 15 & 43 & 41 & 13 \\
Part-Time Study & 7 & 9 & 74 & 7 & 8 & 62 & 8 & 11 & 65 \\
First Semester of Study & 56 & 20 & 24 & 54 & 22 & 31 & 50 & 23 & 34 \\
Repeating Course & 14 & 13 & 33 & 12 & 14 & 33 & 13 & 12 & 18 \\
\hline End-of-Semester University Satisfaction Survey & & & & & & & \\
\hline Responses & 366 & 157 & 51 & 292 & 154 & 44 & 250 & 164 & 48 \\
Response Rate (\%) & 31 & 21 & 31 & 23 & 18 & 26 & 20 & 19 & 38 \\
\hline
\end{tabular}

NB: Semester is abbreviated to SEM and Summer is abbreviated to SUM.

\subsection{DESIGN \& DELIVERY OF WEVS}

WEVs were generated on a Microsoft Surface Pro computer using Screencast-o-matic software to record the screen and voiceover. For manually worked problems, Microsoft OneNote was used to capture handwriting on the screen while some videos included demonstrations in Microsoft Excel. Each WEV focused on a single problem, structured to begin with the instructor reading out the question and summarising how it would be approached. The step-by-step solution was then worked through in detail with the instructor discussing the rationale in real-time. This narration endeavoured to improve students' meta-cognitive monitoring as part of the self-regulated learning cycle by emphasising reasoning and addressing common misconceptions (Nicol \& Macfarlane-Dick, 2006; Zimmerman, 2002). In line with the cognitive theory of multimedia learning, delivering this clarifying information via narration (as opposed to on-screen text) improves learning, as the verbal and visual information can be processed in parallel by the learner's brain (Mayer \& Moreno, 2003). As per the recommendations of Guo et al. (2014) and Mayer (2008), low production quality and a conversational tone were embraced to encourage learner engagement. Recap videos produced for each topic covered the background required to attempt the associated problems. These were designed for the learner to build familiarity with the theory before applying it, thus capitalising on the "pre-training effect" that reduces cognitive load in multimedia environments (Mayer \& Moreno, 2003). Screenshots of a typical WEV are shown in Figure 1.

A total of 40 videos (averaging about 10 minutes in length) were developed and integrated into the course. Problems were scaffolded to cover a range of difficulties and were aligned to the topics delivered throughout the semester. The videos were uploaded to YouTube and embedded into the learning management system (LMS). As videos were not publicly listed, access was only via the LMS. The videos were released to students as follow-up activities after all the tutorials relating to the given topic had run. They were produced on a weekly basis in the first semester of implementation and were then rolled over to subsequent semesters with no changes. 


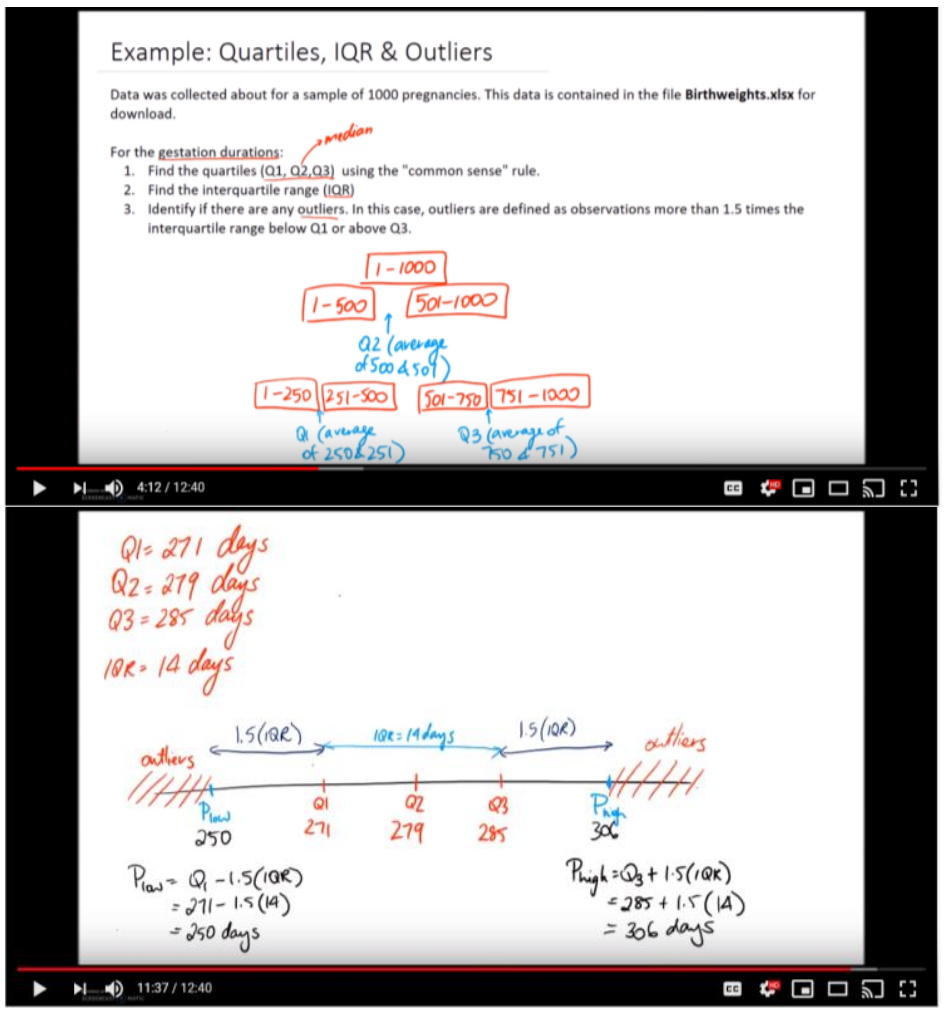

Figure 1. Screenshots from two different time points of a typical WEV.

\subsection{DATA COLLECTION \& ANALYSIS}

Data were collected in line with the approval obtained from the Queensland University of Technology's Human Research Ethics Committee (approval number 1600000165). Video usage, academic performance and student perceptions data were considered. Statistical analysis was performed in SPSS Statistics Version 27.

First, LMS limitations meant usage data could not be collected at the individual student level. Therefore, viewership statistics for the cohort were obtained directly from YouTube's analytics. Specifically, the watch time and view counts were extracted.

Second, students' final percentages achieved in the course were considered, noting $50 \%$ or greater represented a pass. The difference in academic outcomes at the cohort level for students with and without access to WEVs was assessed statistically. To account for the variations in underlying student characteristics (summarised in Table 1), teaching periods were considered independently. Chi-square tests were used to test association between WEV availability (No WEVs/WEVs) and academic outcome (pass/fail). Odds ratios (and the corresponding 95\% confidence intervals) were subsequently used to measure the effect size.

Third, overall course satisfaction was measured through the university's end-of-semester student satisfaction survey. This was administered online with response rates included in Table 1 . The response to the 5-point Likert item "I am satisfied with this course" was used to compare overall student experience before and after WEVs were introduced, given this was the institution's key performance metric and similar measures continue to be used in the broader higher education context (Gannaway et al., 2018). To test the relationship between WEV availability and course satisfaction statistically, the Chi-square test was applied. Here course satisfaction was categorised as agreed with the statement (comprising the agree and strongly agree options) versus neutral or disagreed with the statement (comprising the neutral, disagree, and strongly disagree options). Again, odds ratios were used to measure the effect size, and teaching periods were considered separately due to the similarity in the underlying cohort characteristics.

Finally, to triangulate and provide context for the quantitative findings, a survey probing student perceptions of the WEVs was conducted online at the end of Semester 1, 2018. This was estimated to 
take about 5 minutes to complete and consisted of 17 questions about students' backgrounds, WEV usage motivations, engagement approaches, perceived impact, and preferences. In total, 208 responses were received equating to a $16 \%$ response rate. The proportion of domestic student respondents aligned with the proportion at the course level, however females and school-leavers were over-represented. Of the survey respondents, $78 \%$ stated they had watched WEVs from most to all topics, while $21 \%$ said they had watched videos from a few to half of the topics, and only $1 \%$ had not watched any videos, suggesting that the sample was biased toward video users.

Thematic analysis was applied to students' text responses describing how they interacted with WEVs to uncover strategies used to self-regulate learning within the multimedia environment. This followed an inductive process, as described in Braun and Clarke (2006), that facilitated unconstrained exploration of the data. From the patterns that emerged, responses were coded to four distinct learning strategies of watching passively, pausing to work alongside, watching specific parts according to selfdetermined needs, and using WEVs to support attempts at related problems. These represent increasingly developed learning strategies that align with moving from surface, to deep, and then transfer learning within the Model of Learning proposed by Hattie \& Donoghue (2016). Passively watching WEVs corresponds to a low-level strategy, suitable for developing surface level knowledge like reproducing facts and ideas. Pausing to solve WEV problems independently and tailoring WEV viewing to self-determined needs represent deep learning strategies as they support students to "develop understanding and make sense of what they are learning" (Hattie \& Donoghue, 2016, p. 2). Students using the WEVs to facilitate attempts at other problems exemplifies a high-level transfer learning strategy where students can demonstrate the application of concepts to new, unfamiliar problems. Where students discussed more than one of the identified strategies, the comment was coded to each.

\section{RESULTS AND DISCUSSION}

\subsection{WEV USAGE}

Viewership statistics show WEVs were heavily utilised, with approximately 47,000 views and 165 days of continuous viewing time recorded across the three WEV cohorts (Table 2). Normalised on a per student basis, usage was greatest amongst the Semester 1 and 2 cohorts, aligning with the figures reported by Lai et al. (2017) and Dart, Pickering, et al. (2020), who introduced similarly sized sets of WEVs into undergraduate business statistics and engineering courses respectively. Viewership in the Summer Semester, however, was depressed. This may be explained by the smaller cohort size benefitting from improved interactions among students and the instructor, meaning the face-to-face component became a larger driver of student learning (Mulryan-Kyne, 2010; Owston et al., 2019). Furthermore, Summer Semester cohorts had historically performed better academically (see below), implying these students may have had a reduced need for supplementary WEV content to support their learning.

Table 2. Overall usage of WEVs.

\begin{tabular}{lccc}
\hline Teaching Period in 2018 & Semester 1 & Semester 2 & Summer \\
\hline Total Viewing Time in Days & 111.1 & 49.8 & 3.8 \\
Total Views & 31378 & 14506 & 1104 \\
Average Minutes Viewed per Student & 127 & 82 & 43 \\
Average Views per Student & 24.8 & 16.6 & 8.7 \\
\hline
\end{tabular}

Figure 2 shows WEV viewership over time. It is clear viewership is closely related to the summative assessment schedule through the peaks present in the days leading up to each submission deadline. Furthermore, the size of the peaks is positively associated with the weightings of the assessment items (although this is more volatile for the smaller Summer Semester). The link between usage and assessment was also supported by the WEV survey. Here students overwhelmingly reported assessment as the most dominant usage motivator, with $91 \%$ using the WEVs for homework assignments, $85 \%$ for the research project, and $83 \%$ for exam revision. This is contrasted against other usage reasons of 
clarifying understanding (72\%), catching-up after a missed class (47\%), and additional practice questions (24\%).
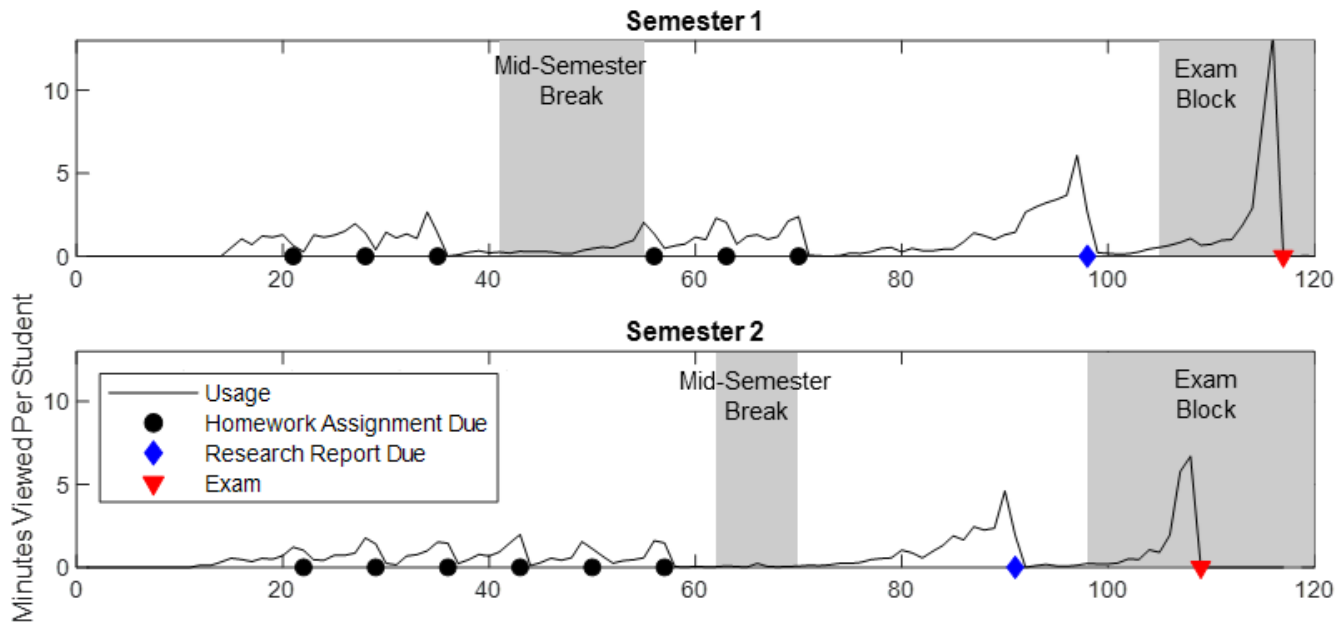

Summer Semester

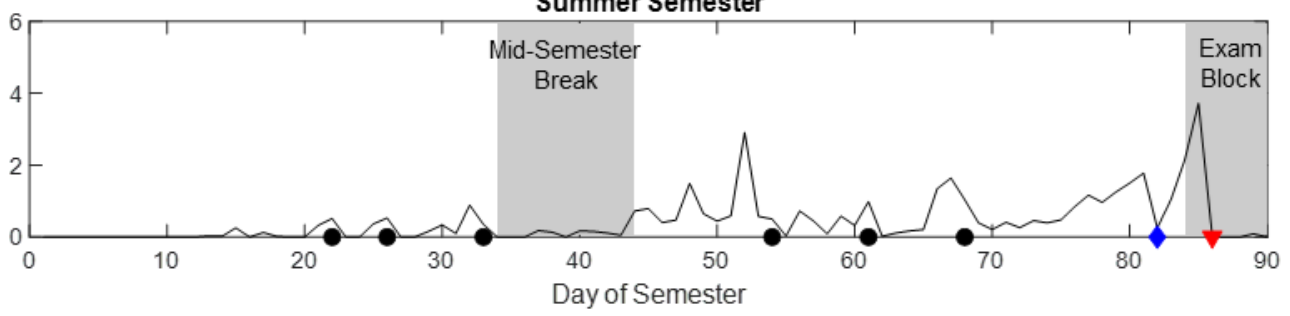

Figure 2. Daily minutes viewed per student over each teaching period in 2018; grey shaded areas show mid-semester break and exam block.

The WEV survey also asked students about factors preventing them from using WEVs more. The key reasons, each given by about a third of respondents, were lack of time, watched every video (ran out of content), and already understood the subject matter. Very few students reported a barrier to engagement was not knowing the WEVs existed.

\subsection{STUDENTS' ACADEMIC PERFORMANCE}

As LMS limitations meant WEV usage could not be tracked to the individual (and thus linked with their grade), academic performance was assessed at the cohort level. Teaching periods were considered in isolation due to the comparability of student characteristics (see Table 1). Figure 3 shows the distribution of final percentages achieved in the course by cohorts with and without access to WEVs, recalling that passing the course required $50 \%$ or greater and students who withdrew from the course after the academic census failed but did not record a final percentage so are grouped separately. Students who failed through course withdrawal did not record a final percentage. Table 3 summarises academic outcomes as well as results of statistical testing. This shows cohorts with access to the WEVs had higher median final percentages and greater pass rates than those without WEV access. Applying the Chisquare test of association between WEV availability and pass/fail outcome shows strong evidence of a relationship between these variables for Semester 1 and 2 teaching periods, but association is weaker for the Summer Semester. Examining the odds ratio as a measure of effect size indicates Semester 1 and 2 students with WEV access had approximately 1.2 to 1.3 times the odds of passing compared those without access. Moreover, the lower bound of the $95 \%$ confidence interval for each odds ratio is greater than 1, providing further support for the significance of this relationship. The odds ratio for the Summer Semester implies that students with WEV access had about 1.7 times the odds of passing than those without access, but the confidence interval for this estimate is wide. Contributing to this result is the smaller sample size for the Summer Semester. Thus, there are indications WEVs positively influenced academic performance outcomes in Summer, but statistical evidence is weaker. 

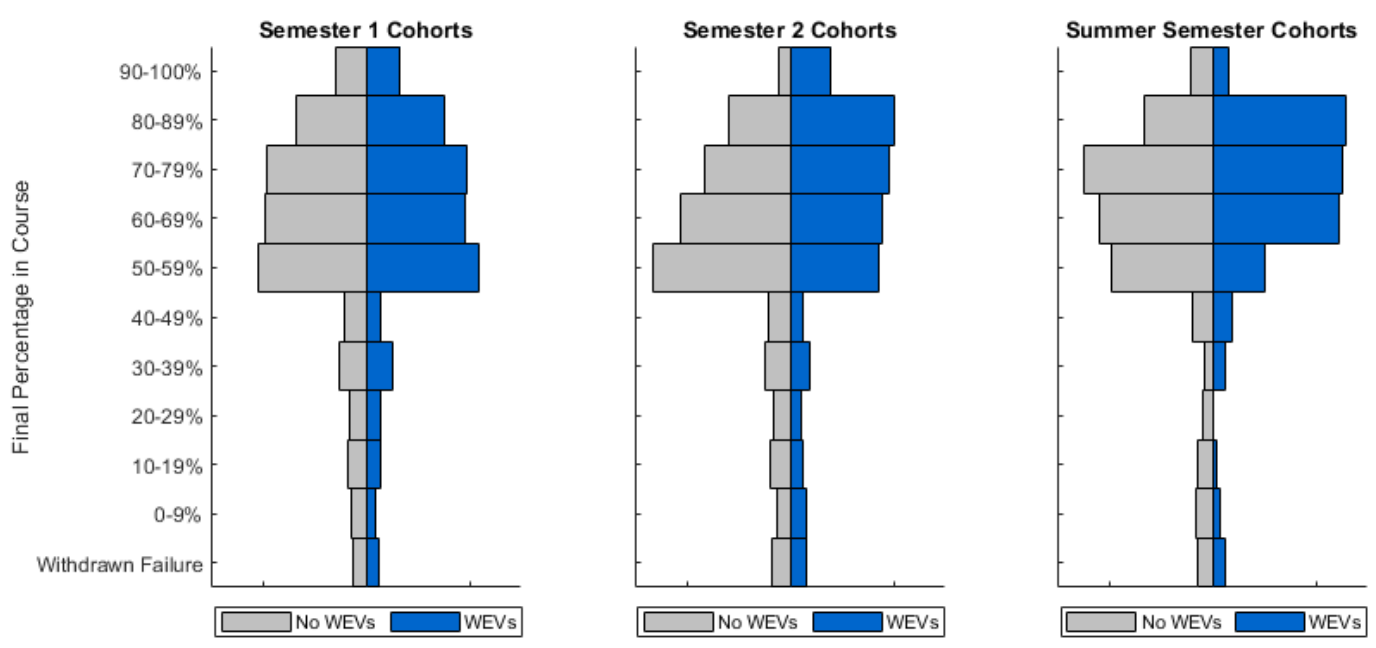

Figure 3. Final percentage distribution for cohorts without and with access to WEVs by teaching period.

Table 3. Summary of academic outcomes and statistical test results comparing cohorts without and with access to WEVs by teaching period.

\begin{tabular}{|c|c|c|c|c|c|c|}
\hline \multirow[b]{2}{*}{ Attribute } & \multicolumn{2}{|c|}{ Semester 1} & \multicolumn{2}{|c|}{ Semester 2} & \multicolumn{2}{|c|}{ Summer } \\
\hline & No WEVs & WEVs & No WEVs & WEVs & No WEVs & WEVs \\
\hline \multicolumn{7}{|c|}{ Final Percentage Achieved in Course } \\
\hline Median & 65 & 66 & 61 & 69 & 68 & 71.5 \\
\hline Quartile 1 & 50 & 51 & 50 & 53 & 55 & 65 \\
\hline Quartile 3 & 77 & 78 & 75 & 81 & 77 & 81 \\
\hline \multicolumn{7}{|c|}{ Pass/Fail Outcomes } \\
\hline Failed & 502 & 222 & 340 & 151 & 54 & 13 \\
\hline Passed & 1921 & 1041 & 1260 & 724 & 280 & 114 \\
\hline Pass Rate & $79.3 \%$ & $82.4 \%$ & $78.8 \%$ & $82.7 \%$ & $83.8 \%$ & $89.8 \%$ \\
\hline \multicolumn{7}{|c|}{ Pearson Chi-Square Test } \\
\hline Value & \multicolumn{2}{|c|}{5.189} & \multicolumn{2}{|c|}{5.671} & \multicolumn{2}{|c|}{2.606} \\
\hline Significance & \multicolumn{2}{|c|}{0.023} & \multicolumn{2}{|c|}{0.017} & \multicolumn{2}{|c|}{0.106} \\
\hline \multicolumn{7}{|c|}{ Odds Ratio (Failed/Passed) } \\
\hline Value & \multicolumn{2}{|c|}{1.225} & \multicolumn{2}{|c|}{1.294} & \multicolumn{2}{|c|}{1.691} \\
\hline 95\% CI Lower & \multicolumn{2}{|c|}{1.029} & \multicolumn{2}{|c|}{1.046} & \multicolumn{2}{|c|}{0.889} \\
\hline 95\% CI Upper & \multicolumn{2}{|c|}{1.460} & \multicolumn{2}{|c|}{1.600} & \multicolumn{2}{|c|}{3.218} \\
\hline
\end{tabular}

$\mathrm{NB}:$ (1) students who recorded a withdrawn fail outcome are excluded from the final percentage descriptive statistics, and (2) confidence interval is abbreviated to CI.

It must be acknowledged that a limitation of comparing the cohorts with and without WEVs is that data were collected in real course environments, so isolating the impact of WEVs from confounding factors is challenging. Overall, however, student cohorts and staffing within each teaching period, the course content, and assessment were consistent, suggesting the major change of introducing WEVs was responsible for the increase. The measured improvement also aligns with student perceptions captured through the WEV survey. Here 94\% of respondents believed (77\% strongly) that WEVs improved their understanding of course content, while $94 \%$ believed (75\% strongly) using WEVs contributed to them obtaining a better course grade. The reasons for improved performance can be unpacked further through examining students' engagement strategies. 


\subsection{STUDENTS' ENGAGEMENT STRATEGIES}

Whether students were employing active learning strategies when engaging with WEVs was explored through thematic analysis of student survey responses. Through this process, four key learning strategies were identified with sample comments aligned to each strategy shown in Table 4.

Table 4. Learning strategies for interacting with the WEVs obtained from thematic analysis.

\begin{tabular}{|c|c|c|}
\hline \multicolumn{2}{|c|}{$\begin{array}{l}\text { Learning Strategy } \\
\text { (\% of comments) }\end{array}$} & $\begin{array}{l}\text { Sample Responses for How Students Typically Interacted with } \\
\text { WEVs (Other Learning Strategies Mentioned in Response) }\end{array}$ \\
\hline 1 & $\begin{array}{l}\text { Watching passively } \\
(13 \%)\end{array}$ & $\begin{array}{l}\text { "Watch the whole video without skipping" } \\
\text { "Watch and focus [on] the process to gain an understanding of how to do it } \\
\text { [the problem]" } \\
\text { "I'd usually end up watching the whole video" } \\
\text { "Watched entire video once, and then watched video again with pausing as } \\
\text { I completed the relevant questions." (Strategy 2) } \\
\text { "Watched the supplementary video through then re-watched parts I didn't } \\
\text { comprehend." (Strategy 3) }\end{array}$ \\
\hline 2 & $\begin{array}{l}\text { Pausing to work } \\
\text { alongside WEVs } \\
(61 \%)\end{array}$ & $\begin{array}{l}\text { "Often paused or slowed speed of video to work alongside them." } \\
\text { "Watched each video in their entirety, pausing after each step to attempt and } \\
\text { then double checking [against my solution]. I found this extremely } \\
\text { helpful in understanding concepts as I learn by doing." } \\
\text { "Watched while working out, paused to think deeper, played to confirm } \\
\text { thinking." } \\
\text { "Pausing to attempt [on] own and rewinding to re-evaluate some sections." } \\
\text { (Strategy 3) } \\
\text { "Pausing for each step to help me complete it by myself. Skipping over } \\
\text { parts that were not needed for me at the time". (Strategy 3) }\end{array}$ \\
\hline 3 & $\begin{array}{l}\text { Rewinding and } \\
\text { skipping to watch } \\
\text { specific sections } \\
\text { according to self- } \\
\text { determined needs } \\
(54 \%)\end{array}$ & $\begin{array}{l}\text { "I have re-winded to parts if it didn't make sense and skip ahead if I am } \\
\text { struggling on certain step or certain aspect of the question." } \\
\text { "I rewind to review difficult parts, and I skip over the easy parts and skip to } \\
\text { the answer sometimes as well." } \\
\text { "Pausing to attempt on own then rewinding to see where my errors were } \\
\text { made then correcting them." (Strategy 2) } \\
\text { "I rewound the video if I didn't understand something or needed to watch } \\
\text { the example again. I re-watched the videos when doing the assignment } \\
\text { and studying for the exam and would skip to the parts where the } \\
\text { examples were similar to the questions I was doing." (Strategy 4) }\end{array}$ \\
\hline 4 & $\begin{array}{l}\text { Using WEVs to } \\
\text { support attempts at } \\
\text { further problems } \\
(19 \%)\end{array}$ & $\begin{array}{l}\text { "I would watch the videos first. Then I would practice the method on my } \\
\text { own question (which was obviously similar to the example question)." } \\
\text { (Strategy 1) } \\
\text { "I would pause and do what was demonstrated, and usually also pause and } \\
\text { apply the tactics to another question if applicable." (Strategy 2) } \\
\text { "I usually paused to write it all down, and later would attempt other } \\
\text { exercises and correct from looking at my notes of the supplementary } \\
\text { videos." (Strategy 2) } \\
\text { "Do one example during the video (pause after each step) and then do } \\
\text { another example after to ensure that I understand. If I get the second } \\
\text { question wrong, I re-watch it." (Strategy } 2 \text { \& 3) }\end{array}$ \\
\hline
\end{tabular}

Only a small proportion of students typically used the low-level passive watching strategy, and even fewer described using it in isolation. Instead in many cases, students built upon it by attempting presented problems (a higher-level approach) after watching. The strategies of pausing to solve WEV problems independently and tailoring WEV viewing to self-determined needs (by rewinding and skipping) were used by most students. Each is well-suited to deep learning. Pausing allowed students to develop solutions at their own pace, while using the WEVs to confirm the processes, clarify understanding, and provide prompts on next steps when stuck. Students often blended pausing with the 
rewinding and skipping strategy. For example, when students identified a mistake in their own solution, they would often seek to understand why this occurred by re-watching or skipping to the relevant part of the WEV. Finally, a smaller proportion of students described using WEVs to support their attempts at other similar problems, a high-level learning strategy for supporting knowledge transfer (Hattie \& Donoghue, 2016).

In each of the higher-level strategies, it was clear that students were actively self-regulating their learning by continually monitoring whether they had grasped concepts and were adjusting their cognition and behaviours accordingly (Hattie \& Donoghue, 2016; Nicol \& Macfarlane-Dick, 2006). Students valued the implicit feedback they received from WEVs that supported them in making more accurate self-assessments of their learning. This was particularly evident in student comments about the WEV narration. For example, students said the most beneficial aspect of WEVs was "the talking through the problem ... sometimes handwritten scans don't explain where certain formulas or numbers came from while videos did," and, "the explanatory areas (theory) ... these were clearly analysed and reasoned as to why such answers and procedures were used." Thus, it can be argued that the feedback students obtained from WEVs enhanced meta-cognitive monitoring through the performance phase of the self-regulated learning cycle, in turn increasing learner performance.

It is also worth noting that students discussed adjusting their learning strategies over time, such as moving from watching overall videos, to only watching specific parts for clarification or verification, and then applying knowledge to other related problems. Skill level and self-efficacy played a role in strategy selection, evidenced by comments like: "I would watch the examples and then pause just after the explanation of what [the instructor] was going to do and before her actually doing the calculation. I would then attempt that part of the question before resuming to see if I got it right. Once I felt a bit more comfortable with a topic, I would only refer to the videos for clarification of a missing step or incorrect calculation, skipping over irrelevant bits of the video." According to Hattie and Donoghue (2016), effectively facilitating the progression from surface to deep and then transfer learning strategies is associated with improved learning. Consequently, the enhanced academic outcomes observed in this study can also be related to WEVs scaffolding this process.

Finally, steps taken to reduce cognitive load within the multimedia environment contributed to improved learning outcomes. There was strong evidence WEVs enabled students to engage in their learning at a comfortable speed through the video controls of pausing, skipping, and rewinding, while the complementary visual and verbal communication was received positively, "[I liked] being able to see (not only listen to) how the lecturer does the question." Additionally, the conversational delivery was recognised as beneficial for learning, such as, "the [instructor] in the videos was clearly spoken and relatable as she sounds like a uni student also, I believe if it was an older individual that I wouldn't enjoy the videos as much." Thus, the pacing, balanced visual and verbal delivery, and conversational approach of the WEVs worked to reduce cognitive load, in turn supporting learning (Mayer, 2008).

\subsection{STUDENTS' COURSE SATISFACTION}

To assess whether WEVs impacted overall course experiences, student satisfaction before and after WEVs were introduced was considered. The distribution of student satisfaction scores is presented in Figure 4 with outcomes summarised in Table 5. This shows within each teaching period, satisfaction was greatest for those with WEV access. However, cohort size appears influential with the smaller cohorts (in Summer) performing better than the larger cohorts (in Semesters 1 and 2). Applying the Chi-square test of association between WEV availability and satisfaction outcome reveals strong support for a relationship (Table 5). The odds ratios show Semesters 1 and 2 students with access to WEVs had approximately twice the odds of agreeing they were satisfied with the course than those without access, and even the lower bound of the 95\% confidence interval for each odds ratio is highly favourable. The odds ratio for the Summer teaching period can be interpreted as students with WEV access having about 7 times the odds of being satisfied with the course compared to those without access, however the smaller sample size contributes to a wide confidence interval for this estimate. Nonetheless, there is strong support for the favourable difference between groups. 


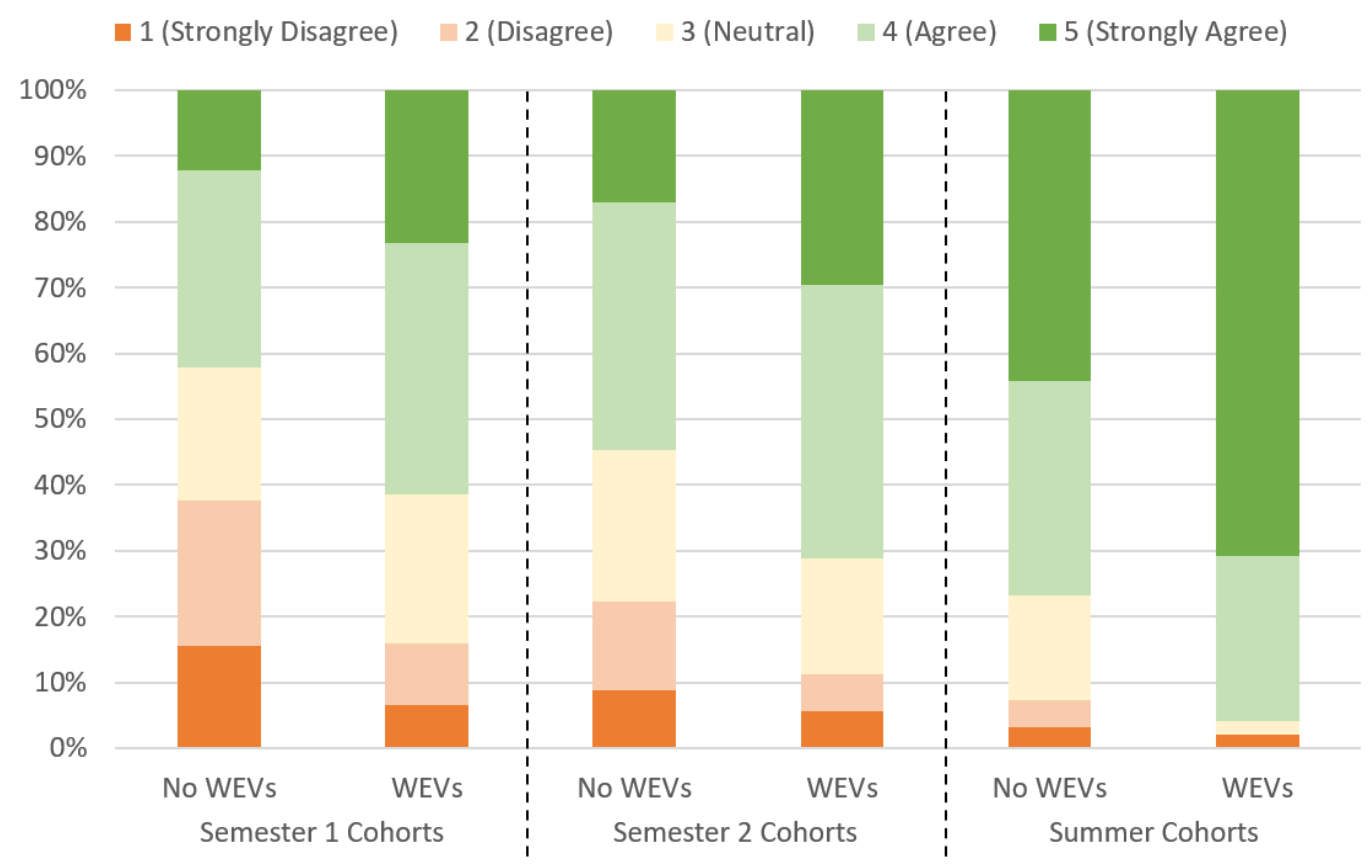

Figure 4. Response to Likert item "I am satisfied with this course" for cohorts without and with access to WEVs by teaching period.

Table 5. Summary of satisfaction outcomes and statistical test results comparing cohorts without and with access to WEVs by teaching period.

\begin{tabular}{|c|c|c|c|c|c|c|}
\hline \multirow[b]{2}{*}{ Attribute } & \multicolumn{2}{|c|}{ Semester 1} & \multicolumn{2}{|c|}{ Semester 2} & \multicolumn{2}{|c|}{ Summer } \\
\hline & No WEVs & WEVs & No WEVs & WEVs & No WEVs & WEVs \\
\hline \multicolumn{7}{|c|}{ Satisfaction Outcome (Response to "I am satisfied with this course") } \\
\hline Agreed & 275 & 151 & 167 & 113 & 73 & 46 \\
\hline Neutral or & 378 & 95 & 138 & 46 & 22 & 2 \\
\hline Disagreed & & & & & & \\
\hline Agreed Rate & $42 \%$ & $61 \%$ & $55 \%$ & $71 \%$ & $77 \%$ & $96 \%$ \\
\hline \multicolumn{7}{|c|}{ Pearson Chi-Square Test } \\
\hline Value & \multicolumn{2}{|c|}{26.61} & \multicolumn{2}{|c|}{11.626} & \multicolumn{2}{|c|}{8.235} \\
\hline Significance & \multicolumn{2}{|c|}{0.000} & \multicolumn{2}{|c|}{0.001} & \multicolumn{2}{|c|}{0.004} \\
\hline \multicolumn{7}{|c|}{ Odds Ratio (Neutral or Disagreed/Agreed) } \\
\hline Value & \multicolumn{2}{|c|}{2.185} & \multicolumn{2}{|c|}{2.030} & \multicolumn{2}{|c|}{6.932} \\
\hline 95\% CI Lower & \multicolumn{2}{|c|}{1.619} & \multicolumn{2}{|c|}{1.347} & \multicolumn{2}{|c|}{1.556} \\
\hline 95\% CI Upper & \multicolumn{2}{|c|}{2.949} & \multicolumn{2}{|c|}{3.060} & \multicolumn{2}{|c|}{30.873} \\
\hline
\end{tabular}

NB. (1) No cell in the contingency tables had expected counts of less than 5, and (2) Confidence interval is abbreviated to CI.

As with the academic performance comparison above, variability of student cohorts is recognised as a factor which impacts the strength of this conclusion. Additionally, the generalisability of the finding is limited by the sample size. The WEV survey also showed students felt favourably toward the WEVs, with $94 \%$ of students agreeing ( $83 \%$ strongly) they would use WEVs if they were available in other similar courses.

How student experiences were enhanced can be related to students' descriptions of their learning approaches. For example, students frequently used the video controls to manage the pace of learning (Table 4) where it was noted that WEVs acted as a timely and effective support mechanism, such as: "[WEVs] made the unit a lot easier to understand and also lowered my stress levels as I know I can 
revert back to them if I get confused," and "these videos helped me additionally outside of the tute [tutorial] without having to bother the staff in their consultation times."

\section{DISCUSSION}

\subsection{SUMMARY}

This study investigated the impact of WEVs as a blended learning approach to enhancing student outcomes and learning experiences in an introductory business statistics course taken by 2265 students over three semesters. Impact was evaluated using video usage, academic performance, and student survey data.

Students heavily utilised the WEVs, especially in the lead-up to assessment due dates. Furthermore, the extent to which students engaged was mediated by the weighting of the assessment. Brown and Race (2013) argue assessment is a core driver of learning in higher education because, unlike other learning activities, students are absolutely required to engage with assessment to achieve their degrees. Consequently, when students are managing competing priorities, they can become highly strategic about dedicating their time only to learning activities which "count" directly toward their final grades (Brown \& Race, 2013). This mentality is evident in the above results where students engaged with WEVs primarily in relation to assessment, and the extent to which this occurred was mediated against the item's relative contribution to final grade. Similar usage patterns have been described in previous WEV studies such as Belski (2011), Key and Paskevicius (2015), and Dart, Pickering et al. (2020). It is also important to highlight that technological issues were not observed in study, despite it being a concern elsewhere in the literature (Chester et al., 2011; DeVaney, 2009; Key \& Paskevicius, 2015). This was likely aided by the delivery via YouTube which is a user-friendly platform that adjusts playback according to internet speed and is optimised for use across different devices. Additionally, awareness of the WEVs did not present as a challenge, which contrasts with several other similar studies (Ahmad et al., 2013; Chester et al., 2011; Dart, Cunningham-Nelson et al., 2020; Martin, 2016).

The introduction of the videos resulted in improved academic performance for the WEV cohorts. This aligns with the literature, which supports a clear relationship between WEV usage and improved academic performance (Belski, 2011; He et al., 2012; Key \& Paskevicius, 2015; Lai et al., 2017; Loch et al., 2014; Martin, 2016). The improvement can be attributed to students overwhelmingly utilising active learning strategies when engaging with WEVs, given cognitive effort (applied to self-regulate learning as well as select, organise, and integrate information) is linked to enhanced learning outcomes, particularly in STEM disciplines (Deslauriers et al., 2019; Freeman et al., 2014).

A dramatic improvement in course satisfaction was also observed, in line with other similar studies (Dart, Pickering, et al., 2020; DeVaney, 2009). The satisfaction improvement was most pronounced in the larger cohorts, which is consistent with the literature that shows student satisfaction tends to be negatively correlated with cohort size due to the greater difficulties faced generating high-quality student experiences in large-enrolment courses (Gannaway et al., 2018; Mulryan-Kyne, 2010; Owston et al., 2019). Given time pressure (Kinkead et al., 2016) and fear of seeking help (Hamid \& Sulaiman, 2014) are known to contribute to statistics anxiety, WEVs addressing these challenges would have played an important role in enhancing students' course experiences. This is also expected to have a longer-term impact, given those students who develop positive perceptions of statistics during their studies are more likely to effectively employ statistics in their future practice (Schau \& Emmioğlu, 2012; Songsore \& White, 2018).

\subsection{WEV SUITABILITY TO LARGE-ENROLMENT COURSES}

WEVs are well-suited to large-enrolment courses as they can take full advantage of economies of scale. For example, WEVs have a fixed cost associated with their production, however, there is no cost in providing them to each additional student within a cohort. This can be extended further with strategic content choices that allow WEVs to be rolled over to subsequent semesters. This requires content is relevant over time, but large-enrolment courses are often at an introductory level (Owston et al., 2019) and thus covering fundamentals that are unlikely to change. Moreover, large-enrolment courses tend to be run more regularly over the academic year, facilitating further returns through the repeated use. It is 
worth emphasising that the experience offered by WEVs remains consistent even as cohort size grows. This is distinct from face-to-face learning environments where interactions become increasingly passive as student to instructor ratios escalate (Mulryan-Kyne, 2010; Owston et al., 2019).

Large-enrolment courses are also excellent candidates for investment in self-serve support - by addressing frequent issues at this level, demand for more resource-intensive support (such as email enquiries, individual consultations, and academic skills services) can be substantially reduced. WEVs are well-suited to facilitating this, given they can be developed to specifically target areas that students regularly seek help for. Additionally, the asynchronous delivery enables highly efficient and timely support (including outside of regular working hours for staff) (Lai et al., 2017). Anecdotal reports from teaching and support staff in the present study indicated reduced demands for support occurred when the WEVs were introduced, particularly for the peer learning service operated by the faculty. Thus WEVs can complement formal support services like drop-in centres, which are becoming increasingly popular for addressing the decline in commencing students' mathematical skills (Intepe \& Sheaman, 2020).

Finally, large-enrolment courses typically encounter high levels of cohort diversity (Mulryan-Kyne, 2010), stemming from introductory subject matter being compulsory for students from a range of majors (Owston et al., 2019). Furthermore, students typically attempt large-enrolment courses early in their degrees, so are still undergoing the transition to higher education (Dart \& Spratt, 2021). WEVs are wellsuited to these situations given they can accommodate students with widely varying levels of prior knowledge, interests, and confidence with the subject matter. This is achieved through students exercising their personal agency in selecting content and learning strategies, thus enabling students to customise their learning to their self-determined needs.

\subsection{LIMITATIONS AND FUTURE WORK}

This study has highlighted the significant potential of WEVs in improving students' learning outcomes and experiences. However, the study has limitations that constrain the strength and generalisability of the findings. In particular, the live course environment introduced confounding factors (such as variations in student backgrounds and teaching teams) that complicate statistical comparisons. Moreover, the inability to link WEV usage to an individual and thus their final grade, meant academic performance comparisons could only be made at the cohort level. Another key constraint was the small sample size responding to the surveys.

Future work should aim to extend the findings of this research, while addressing the key limitations. As the WEV concept has applicability beyond introductory statistics education within the Australian undergraduate setting, future work should explore WEV impact in other course contexts. This would broaden understanding of how subject matter, level of the course, student backgrounds, and educational culture influence video usage, academic performance, and student experiences. Further evidence would also facilitate a clearer consensus on the level of impact WEVs have, given the measurement limitations of live course environments where variability in students and circumstances cannot be wholly controlled. It would also be interesting to examine how different types of students benefit from and use WEVs. For example, native speakers versus those with English as an additional language, and students who lack prerequisite knowledge versus those with strong domain-specific knowledge at commencement.

\section{ACKNOWLEDGEMENTS}

The author would like to thank the Data Analysis teaching team who promoted and supported the videos embedded in the course.

\section{REFERENCES}

Ahmad, T. B. T., Doheny, F., Harding, N., \& Faherty, S. (2013). How instructor-developed screencasts benefit college students' learning of maths: Insights from an Irish case study. The Malaysian Online Journal of Educational Technology, 1(4), 12-25. http://research.thea.ie/handle/20.500.12065/2888 
Ali, A. Z., \& Iqbal, F. (2012). Statistics anxiety among psychology graduates: An analysis. International Proceedings of Economics Development Research, 53(25), 113-117. http://www.ipedr.com/vol53/025-BCPS2012-C10026.pdf

Association to Advance Collegiate Schools of Business. (2018). 2013 Eligibility procedures and accreditation standards for business accreditation. https://www.aacsb.edu//media/aacsb/docs/accreditation/business/standards-and-tables/2018-business-standards.ashx

Ayres, P., \& Sweller, J. (2013). The worked example effect. In J. Hattie \& E. M. Anderman (Eds.), International guide to student achievement (pp. 408-410). Routledge.

Barrington, F., \& Evans, M. (2016). Year 12 mathematics participation in Australia: The last ten years. https://amsi.org.au/?publications=participation-in-year-12-mathematics-2006-2016

Belski, I. (2011). Dynamic and static worked examples in student learning. Developing engineers for social justice: Community involvement, ethics \& sustainability. In Proceedings of the 22nd Annual Conference of the Australasian Association for Engineering Education, Fremantle, Western Australia, December 5-7 (pp. 396-401).

Berenson, M. L., Ramnarayanan, R., \& Oppenheim, A. (2015). Assessing the disconnect between grade Eepectation and achievement in a business statistics course. Journal of Education for Business, 90(2), 72-80. https://doi.org/10.1080/08832323.2014.973828

Braun, V., \& Clarke, V. (2006). Using thematic analysis in psychology. Qualitative Research in Psychology, 3(2), 77-101. https://doi.org/10.1191/1478088706qp063oa

Brown, S., \& Race, P. (2013). Using effective assessment to promote learning. In L. Hunt \& D. Chalmers (Eds.), University teaching in focus: A learning-centred approach (Vol. 2, pp. 74-91). Routledge.

Brynjolfsson, E., \& McElheran, K. (2016). The rapid adoption of data-driven decision-making. American Economic Review, 106(5), 133-139. http://dx.doi.org/10.1257/aer.p20161016

Chester, A., Buntine, A., Hammond, K., \& Atkinson, L. (2011). Podcasting in education: Student attitudes, behaviour and self-efficacy. Journal of Educational Technology \& Society, 14(2), 236247. https://www.jstor.org/stable/jeductechsoci.14.2.236? seq=1

Dart, S., Cunningham-Nelson, S., \& Dawes, L. (2020). Understanding student perceptions of worked example videos through the technology acceptance model. Computer Applications in Engineering Education, 28(5), 1278-1290. https://doi.org/10.1002/cae.22301

Dart, S., Pickering, E., \& Dawes, L. (2020). Worked example videos for blended learning in undergraduate engineering. Advances in Engineering Education, 8(2), 1-22. https://advances.asee.org/worked-example-videos-for-blended-learning-in-undergraduateengineering/

Dart, S., \& Spratt, B. (2021). Personalised emails in first-year mathematics: Exploring a scalable strategy for improving student experiences and outcomes. Student Success, 12(1), 1-12. https://doi.org/10.5204/ssj.1543

Deslauriers, L., McCarty, L. S., Miller, K., Callaghan, K., \& Kestin, G. (2019). Measuring actual learning versus feeling of learning in response to being actively engaged in the classroom. Proceedings of the National Academy of Sciences, 116(39), 19251-19257. https://doi.org/10.1073/pnas.1821936116

DeVaney, T. A. (2009). Impact of video tutorials in an online educational statistics course. Journal of Online Learning and Teaching, 5(4), 600-608.

Dziuban, C., Graham, C. R., Moskal, P. D., Norberg, A., \& Sicilia, N. (2018). Blended learning: the new normal and emerging technologies. International Journal of Educational Technology in Higher Education, 15(3), 1-16. https://doi.org/10.1186/s41239-017-0087-5

Freeman, S., Eddy, S. L., McDonough, M., Smith, M. K., Okoroafor, N., Jordt, H., \& Wenderoth, M. P. (2014). Active learning increases student performance in science, engineering, and mathematics. Proceedings of the National Academy of Sciences, 111(23), 8410-8415. https://doi.org/10.1073/pnas.1319030111

Gannaway, D., Green, T., \& Mertova, P. (2018). So how big is big? Investigating the impact of class size on ratings in student evaluation. Assessment \& Evaluation in Higher Education, 43(2), 175184. https://doi.org/10.1080/02602938.2017.1317327

Guo, P. J., Kim, J., \& Rubin, R. (2014). How video production affects student engagement: An empirical study of MOOC videos. In M. Sahami (Ed.), Learning at Scale 2014: Proceedings of the 
first ACM conference on Learning @ Scale, Atlanta, Georgia, March 4-5 (pp. 41-50). https://dl.acm.org/doi/10.1145/2556325.2566239

Hamid, H. S. A., \& Sulaiman, M. K. (2014). Statistics anxiety and achievement in a statistics course among psychology students. The Journal of Behavioral Science, 9(1), 55-66. https://doi.org/10.14456/ijbs.2014.11

Hattie, J. A., \& Donoghue, G. M. (2016). Learning strategies: A synthesis and conceptual model. npj Science of Learning, 1, 16013. https://doi.org/10.1038/npjscilearn.2016.13

He, Y., Swenson, S., \& Lents, N. (2012). Online video tutorials increase learning of difficult concepts in an undergraduate analytical chemistry course. Journal of Chemical Education, 89(9), 1128-1132. https://doi.org/10.1021/ed200685p

Intepe, G., \& Sheaman, D. (2020). Developing statistical understanding and overcoming anxiety via drop-in consultations. Statistics Education Research Journal, 19(1), 149-166. https://doi.org/10.52041/serj.v19i1.127

Kant, J. M., Scheiter, K., \& Oschatz, K. (2017). How to sequence video modeling examples and inquiry tasks to foster scientific reasoning. Learning and Instruction, 52, 46-58. https://doi.org/10.1016/j.learninstruc.2017.04.005

Karabulut-Ilgu, A., Jaramillo Cherrez, N., \& Jahren, C. T. (2018). A systematic review of research on the flipped learning method in engineering education. British Journal of Educational Technology, 49(3), 398-411. https://doi.org/10.1111/bjet.12548

Kay, R. H. (2012). Exploring the use of video podcasts in education: A comprehensive review of the literature. Computers in Human Behavior, 28(3), 820-831. https://doi.org/10.1016/j.chb.2012.01.011

Key, J., \& Paskevicius, M. (2015). Investigation of video tutorial effectiveness and student use for general chemistry laboratories. Journal of Applied Learning Technology, 5(4), 14-21. https://viurrspace.ca/handle/10613/2801

King, D., \& Cattlin, J. (2015). The impact of assumed knowledge entry standards on undergraduate mathematics teaching in Australia. International Journal of Mathematical Education in Science and Technology, 46(7), 1032-1045. https://doi.org/10.1080/0020739X.2015.1070440

Kinkead, K. J., Miller, H., \& Hammett, R. (2016). Adult perceptions of in-class collaborative problem solving as mitigation for statistics anxiety. The Journal of Continuing Higher Education, 64(2), 101-111. https://doi.org/10.1080/07377363.2016.1178057

Kitsantas, A., \& Chow, A. (2007). College students' perceived threat and preference for seeking help in traditional, distributed, and distance learning environments. Computers \& Education, 48(3), 383395. https://doi.org/10.1016/j.compedu.2005.01.008

Lai, G., Zhu, Z., \& Williams, D. (2017). Enhance students' learning in business statistics class using video tutorials. Journal of Teaching Learning with Technology, 6(1), 31-44. https://doi.org/10.14434/jotlt.v6n1.21161

Lloyd, S. A., \& Robertson, C. L. (2011). Screencast tutorials enhance student learning of statistics. Teaching of Psychology, 39(1), 67-71. https://doi.org/10.1177/0098628311430640

Loch, B., Jordan, C. R., Lowe, T. W., \& Mestel, B. D. (2014). Do screencasts help to revise prerequisite mathematics? An investigation of student performance and perception. International Journal of Mathematical Education in Science and Technology, 45(2), 256-268. https://doi.org/10.1080/0020739X.2013.822581

Ma'arop, A. H., \& Embi, M. A. (2016). Implementation of blended learning in higher learning institutions: A review of the literature. International Education Studies, 9(3), 41-52. https://doi.org/10.5539/ies.v9n3p41

Martin, P. A. (2016). Tutorial video use by senior undergraduate electrical engineering students. Australasian Journal of Engineering Education, 21(1), 39-47. https://doi.org/10.1080/22054952.2016.1259027

Mayer, R. E. (2008). Applying the science of learning: Evidence-based principles for the design of multimedia instruction. American Psychologist, 63(8), 760-769.

Mayer, R. E., \& Moreno, R. (2003). Nine ways to reduce cognitive load in multimedia learning. Educational Psychologist, 38(1), 43-52. https://doi.org/10.1207/S15326985EP3801_6 
Mohamad Ali, A. Z., Samsudin, K., Hassan, M., \& Sidek, S. F. (2011). Does screencast teaching software application need narration for effective learning? Turkish Online Journal of Educational Technology, 10(3), 76-82. http://www.tojet.net/articles/v10i3/1039.pdf

Moos, D. C., \& Bonde, C. (2016). Flipping the classroom: Embedding self-regulated learning prompts in videos. Technology, Knowledge and Learning, 21(2), 225-242. https://doi.org/10.1007/s10758015-9269-1

Moskal, P., Dziuban, C., \& Hartman, J. (2013). Blended learning: A dangerous idea? The Internet and Higher Education, 18, 15-23. https://doi.org/10.1016/j.iheduc.2012.12.001

Mulryan-Kyne, C. (2010). Teaching large classes at college and university level: Challenges and opportunities. Teaching in Higher Education, 15(2), 175-185. http://doi.org/10.1080/13562511003620001

Nguyen, T. H., Charity, I., \& Robson, A. (2016). Students' perceptions of computer-based learning environments, their attitude towards business statistics, and their academic achievement: implications from a UK university. Studies in Higher Education, 41(4), 734-755. https://doi.org/10.1080/03075079.2014.950562

Nicol, D. J., \& Macfarlane-Dick, D. (2006). Formative assessment and self-regulated learning: A model and seven principles of good feedback practice. Studies in Higher Education, 31(2), 199-218. https://doi.org/10.1080/03075070600572090

Office of the Chief Scientist, \& Australian Mathematical Institute. (2020). Mapping university prerequisites in Australia. https://www.chiefscientist.gov.au/sites/default/files/202009/mapping_university_prerequisites_in_australia.pdf

Onwuegbuzie, A. J., \& Wilson, V. A. (2003). Statistics anxiety: Nature, etiology, antecedents, effects, and treatments: A comprehensive review of the literature. Teaching in Higher Education, 8(2), 195209. https://doi.org/10.1080/1356251032000052447

Owston, R., York, D. N., \& Malhotra, T. (2019). Blended learning in large enrolment courses: Student perceptions across four different instructional models. Australasian Journal of Educational Technology, 35(5), 29-45. https://doi.org/10.14742/ajet.4310

Schau, C., \& Emmioğlu, E. (2012). Do introductory statistics courses in the United States improve students' attitudes? Statistics Education Research Journal, 11(2), 86-94. https://doi.org/10.52041/serj.v11i2.331

Songsore, E., \& White, B. J. (2018). Students' perceptions of the future relevance of statistics after completing an online introductory statistics course. Statistics Education Research Journal, 17(2), 120-140. https://doi.org/10.52041/serj.v17i2.162

Sweller, J., van Merriënboer, J. J., \& Paas, F. (2019). Cognitive architecture and instructional design: 20 years later. Educational Psychology Review, 1-32. https://doi.org/10.1007/s10648-019-09465-5

Vaughan, N. (2007). Perspectives on blended learning in higher education. International Journal on ELearning, 6(1), 81-94. https://www.learntechlib.org/primary/p/6310/

Zimmerman, B. J. (2002). Becoming a self-regulated learner: An overview. Theory into Practice, 41(2), 64-70. https://doi.org/10.1207/s15430421tip4102_2

SARAH DART

Learning \& Teaching Unit

Queensland University of Technology

GPO Box 2434

Brisbane QLD 4001

Australia 